\title{
Acrylamide in food: mechanisms of formation and influencing factors during heating of foods
}

\author{
Hans Lingnert', Spiros Grivas², Margaretha Jägerstad ${ }^{3}$, Kerstin Skog ${ }^{4}$, \\ Margareta Törnqvist ${ }^{5}$ and Per $\AA^{\text {man }}{ }^{3}$
}

\begin{abstract}
'SIK, The Swedish Institute for Food and Biotechnology, Göteborg, Sweden; ${ }^{2}$ Department of Biosciences, Karolinska Institute and Södertörn University College, Stockholm, Sweden; ${ }^{3}$ Department of Food Science, University of Agricultural Sciences, Uppsala, Sweden; ${ }^{4}$ Department of Applied Nutrition and Food Chemistry, University of Lund, Sweden; ${ }^{5}$ Department of Environmental Chemistry, University of Stockholm, Sweden
\end{abstract}

\begin{abstract}
A bstract
Background: In April 2002, the Swedish National Food Administration and a scientific group at the University of Stockholm jointly announced that they had shown acrylamide to be formed during the preparation of food and found it to occur in many foodstuffs. These new findings were clearly of concern to many types of industrial food processing as well as to home cooking. The Swedish Food Federation (Li) initiated and financed the formation of an expert committee to look into the chemical mechanisms. The present review is the final report of that expert committee.

Design: The study identified, examined and put together facts and present knowledge on reaction routes for acrylamide formation in food and causal connections to cooking and food processing conditions. The results are based on literature surveys, examination of the analytical data published by the Swedish National Food Administration and other follow-up studies, contacts with international scientific networks, and observations from food companies.

Results: The exact chemical mechanism(s) for acrylamide formation in heated foods is unknown. Several plausible mechanistic routes may be suggested, involving reactions of carbohydrates, proteins/amino acids, lipids and probably also other food components as precursors. With the data and knowledge available today it is not possible to point out any specific routes, or to exclude any possibilities. It is likely that a multitude of reaction mechanisms is involved. Acrolein is one strong precursor candidate, the origin of which could be lipids, carbohydrates or proteins/amino acids. Acrylamide is a reactive molecule and it can readily react with various other components in the food. The actual acrylamide level in a specific food product, therefore, probably reflects the balance between ease of formation and potential for further reactions in that food matrix. There are indications in support of that the Maillard reaction being an important reaction route for acrylamide formation, but lipid degradation pathways to the formation of acrolein should also be considered.

Conclusions: Reliable analytical methods to measure acrylamide in foods are available. Model studies are needed to identify precursors and reaction route(s) based on current hypotheses and to elucidate possible further reactions between acrylamide and other food components. Studies are needed to optimize formulation and processing conditions to minimize acrylamide levels, taking other product quality properties into consideration.
\end{abstract}

Keywords: Acrylamide, cooking, food processing, heated foods, Maillard reaction.

Received: 3 October 2002; Accepted: 10 October 2002

\section{Acrylamide: some basic facts}

Synonyms: 2-propenamide, ethylene carboxamide, acrylic acid amide, vinyl amide, propenoic acid amide;<smiles>C=CC(N)=O</smiles>

CAS no.: 79-06-1. Molecular mass: 71.09. 
Acrylamide appears as a white crystalline solid, is odourless and has high solubility in water (2155 g $1^{-1}$ water). Its melting point is $84.5^{\circ} \mathrm{C}$, and its boiling point $(25 \mathrm{mmHg}) 125^{\circ} \mathrm{C}\left(192.6^{\circ} \mathrm{C}\right.$ at atmospheric pressure).

Acrylamide is a reactive chemical, which is used as a monomer in the synthesis of polyacrylamides used, for example, in the purification of water and in the formulation of grouting agents. Acrylamide is known as a component in tobacco smoke.

Acrylamide is primarily reactive through its ethylenic double bond. Polymerization of acrylamide occurs through radical reactions with the double bond. Acrylamide could also react as an electrophile by 1,4-addition to nucleophiles, e.g. $\mathrm{SH}$ - or $\mathrm{NH}_{2}$-groups in biomolecules.

Acrylamide is metabolized in the body to glycidamide, a reactive compound formed through epoxidation of the double bond.

The toxicological effects of acrylamide have been studied in animal models. Exposure to acrylamide leads to DNA damage and at high doses neurological and reproductive effects have been observed. Carcinogenic action in rodents has been described, but carcinogenicity to humans has not been demonstrated in epidemiological studies, although it cannot be excluded. The International Agency for Research on Cancer (IARC) has classified acrylamide as "probably carcinogenic to humans" (group 2A). Neurological effects have been observed in humans exposed to acrylamide. The properties, use and toxic effects of acrylamide are reviewed by IARC (1) and the European Union (EU) (2).

\section{Background: how was acrylamide formation in foods observed?}

\section{Reaction product from acrylamide observed in humans}

Compounds that are reactive and therefore short lived in the body can be demonstrated through their stable reaction products (adducts) with biomacromolecules, e.g. haemoglobin $(\mathrm{Hb})$ in blood. The adducts to $\mathrm{Hb}$ are accumulated during the life span of the protein (about 4 months in humans). $\mathrm{Hb}$ adducts are not indicators of toxic action but could be used for exposure measurements and calculation of intake.

A sensitive method for specific measurement of adducts to the $\mathrm{N}$-terminal valines in the globin chains in $\mathrm{Hb}$ and for analysis by gas chromatography-mass spectrometry (GC-MS) has been devel- oped and applied to a wide range of compounds (3, 4). Application of this methodology has shown that an adduct from acrylamide is formed by Michael addition to the ethylenic double bond to $\mathrm{N}$-terminal valine (5). This adduct, $N$-(2-carbamoylethyl)valine, has been measured in blood from acrylamide-exposed humans (5-8) and animals (9). In studies of occupational exposure it has been shown that the adduct also occurs in blood from persons without known exposure $(6,8)$, although at higher levels in smokers (since acrylamide occurs in cigarette smoke).

In connection with studies of the leakage of acrylamide at the Hallandsâs tunnel construction in Sweden, calculations of uptake of acrylamide and evaluation of cancer risk were performed (10). The calculations of uptake (from pharmacokinetic modelling and reaction kinetics) showed that the average background adduct level in unexposed controls would correspond to a daily intake by adults of about $100 \mu \mathrm{g}$ acrylamide, and there was a preliminary indication that this background level could be associated with a considerable cancer risk. The estimated risk seemed to be higher than the risk from "background" exposure of other reactive compounds detected as adducts in persons without known exposure. In this situation it appeared urgent to find the source of the acrylamide adducts regularly observed in non-exposed persons. The occurrence of acrylamide in tobacco smoke and the findings of lower background levels in wild animals (Törnqvist et al., to be published) led to the hypothesis that acrylamide was formed in cooking.

\section{Acrylamide formation during cooking: identification and quantification}

The identification of acrylamide in heated foodstuffs originated from a hypothesis for which both direct and indirect proof was obtained. An animal feeding experiment was performed to test the hypothesis on acrylamide formation during heating of foodstuffs. A strong increase in the acrylamide $\mathrm{Hb}$ adduct level in blood from rats was observed when the animals were fed fried standard feed (11). In this context the identity of the observed $\mathrm{Hb}$ adduct was verified by tandem mass spectrometry (GC-MS/MS) through comparison with isotopesubstituted standards (11).

A GC-MS method for analysis of acrylamide in water (based on bromination) was further developed for the analysis of acrylamide in the animal feed. The content of acrylamide in the fried feed 
was measured and found to be compatible with the increase in the acrylamide $\mathrm{Hb}$ adduct level in the rats.

In following experiments the effect of heating (frying, etc.) on the content of acrylamide in different foodstuffs was investigated (12). The GC-MS method that had been applied in the studies of animal feed was further improved and simplified. This method, based on a well-known procedure for analysis of acrylamide in water, involves bromination of the ethylenic double bond, the dibromopropionamide formed being the analyte. The bromination is performed at ambient temperature and at $\mathrm{pH} \mathrm{1-3.} \mathrm{The} \mathrm{GC-MS} \mathrm{analysis} \mathrm{is} \mathrm{performed}$ at raised temperature. It was found desirable to confirm the results by a milder method for analysis of underivatized acrylamide. This was achieved by the development of a liquid chromatographytandem mass spectrometry (LC-MS/MS) method. The analytical results obtained with these two methods (GC-MS and LC-MS/MS) are in full agreement. Analysis at different conditions with the two methods further supported the conclusion that acrylamide is the analyte. It was shown that acrylamide was formed in a temperature-dependent manner in food. Low contents of acrylamide were found in heated protein-rich foods $\left(5-50 \mu \mathrm{g} \mathrm{kg}^{-1}\right)$ and high contents in carbohydrate-rich foods (100-4000 $\mu \mathrm{g} \mathrm{kg}^{-1}$ ), compared with undetectable levels in unheated or boiled foods.

The fact that in the above animal experiment the formed adduct levels tallied with the dietary intake of acrylamide as analysed in the heated feed, further supports the view that we are really dealing with acrylamide. Similar conclusions can be drawn from adduct levels in humans and human consumption on heated foods (12).

This work was carried out in a collaborative project between Stockholm University and AnalyCen Nordic AB, with development of methods and analysis of acrylamide in food in the latter laboratory. In view of the results obtained, showing high acrylamide contents in carbohydrate-rich commercial foods, the Swedish National Food Administration, in parallel work, developed an LCMS/MS method for acrylamide analysis in food (13). They essentially verified the results and extended the study to a broader range of foodstuffs (http://www.slv.se), and also showed that there was good agreement between the analyses carried out at the two laboratories (13). The results from the studies were jointly announced in Stockholm on 24 April 2002.
Subsequent work verifying and extending the analyses of acrylamide in food, mostly analysed with LC-MS/MS, has been presented from several Food Authorities and other organizations in different countries (e.g. the UK, Norway, the Netherlands, Switzerland, Germany and the USA).

\section{Chemical mechanisms for acrylamide formation}

Food scientists and technologists have had an interest in acrylamide (and/or its derivatives, including polymers), its applications and its possible toxic effects for many years. For example, there are many reports on can coatings and food packaging, food additives (preservatives, artificial sweeteners, etc.) and acrylamide polymers of suitable quality with low residual acrylamide monomer levels that are used in, for example, the USA for treatment of poultry, potato, corn and other wastes, with the resulting concentrated solids used as components of blended animal feeds (14-19).

There are only a few earlier reports on the occurrence of acrylamide in food. For example, acrylamide has been reported to be present in plant material (potatoes, carrots, radish, lettuce, Chinese cabbage, parsley, onions, spinach and rice paddy) (20). In 1 g plant samples, 1.5-100 ng acrylamide could be detected. Acrylamide was also reported to occur in sugar (21). The origin of the detected acrylamide in these foods is not known; it may be exogenous.

To the authors' knowledge, no proposed or proven reaction routes for the formation of acrylamide during food processing have been published. Therefore, described below are the hypotheses that were found to be most relevant and probable in a food processing situation.

(A) Acrolein (2-propenal, $\mathrm{CH}_{2}=\mathrm{CH}-\mathrm{CHO}$ ) is a three-carbon aldehyde and thus recalls the structure of acrylamide $\left[\mathrm{CH}_{2}=\mathrm{CH}-\mathrm{C}(\mathrm{O})-\mathrm{NH}_{2}\right]$. Further, acrolein is known to be formed by:

- transformation of lipids;

- degradation of amino acids and proteins;

- degradation of carbohydrates;

- the Maillard reaction (MR) between amino acids or proteins and carbohydrates.

Therefore, acrolein is a very probable precursor of acrylamide. Simple, fundamental chemical transformations (such as reaction with ammonia liberated from amino acids) can then convert acrolein (or a derivative of it) into acrylamide. The produc- 
tion of acrylamide through the reaction of acrolein with ammonia can be anticipated.

(B) Alternative formation mechanisms of acrylamide do not necessarily involve acrolein. For example, proteins and/or amino acids can, after a series of transformations, such as hydrolyses, rearrangements and decarboxylations, eventually lead to acrylamide.

Processes A and B are complicated and involve multistage reaction mechanisms which may also include free radical reactions to acrolein or acrylamide (23-25).

\section{Acrolein formation from lipids}

When oil is heated at temperatures above the smoke point, glycerol is degraded to acrolein, the unpleasant acrid black and irritating smoke (26$29)$. The formation of acrolein is known to increase with the increase in unsaturation in the oil and to lead to a lowering of the smoke point. The smoke point is higher for oils with a higher content of saturated fatty acids and lower content of polyunsaturated acids. The smoke points for some of the main oils and fats are: palm $240^{\circ} \mathrm{C}$, peanut $220^{\circ} \mathrm{C}$, olive $210^{\circ} \mathrm{C}$, lard and copra $180^{\circ} \mathrm{C}$, sunflower and soyabean $170^{\circ} \mathrm{C}$, corn $160^{\circ} \mathrm{C}$, margarine $150^{\circ} \mathrm{C}$ and butter $110^{\circ} \mathrm{C}$. Usually, the smoke starts to appear on the surface of heated oils before their temperature reaches $175^{\circ} \mathrm{C}$. The oil is first hydrolysed into glycerol and fatty acids and then acrolein is produced by the elimination of water from glycerol by a heterolytic acidcatalysed carbonium ion mechanism followed by oxidation (30):

$$
\mathrm{CH}_{2}(\mathrm{OH})-\underset{\text { Glycerol }}{\mathrm{CH}}(\mathrm{OH})-\mathrm{CH}_{2}(\mathrm{OH}) \rightarrow \mathrm{CH}_{2} \underset{\text { Acrolein }}{\mathrm{CH}}-\mathrm{CHO}
$$

Besides the above-mentioned mechanism for the formation of acrolein from acylglycerols, acrolein can also be produced as a result of oxidation of polyunsaturated fatty acids and their degradation products $(31-34)$. Several aldehydic products (including malondialdehyde, C3-C10 straight chain aldehydes, and $\alpha, \beta$-unsaturated aldehydes, such as 4-hydroxynonenal and acrolein) are known to form as secondary oxidation products of lipids (35). Acrolein was also found to form in $v i_{v o}$ by the metal-catalysed oxidation of polyunsaturated fatty acids, including arachidonic acid (36).

\section{Acrolein formation from amino acids, proteins and carbohydrates}

Several sources for the formation of acrolein are known. It may arise from degradation of amino acids and proteins $(37,38)$, degradation of carbohydrates (39), and the MR between amino acids or proteins and carbohydrates $(40,41)$. Many possible routes for the formation of this three-carbon aldehyde, taking the starting point from many different sugars or amino acids, may be proposed. Its formation from methionine by the Strecker degradation in the frame of the MR is one example. Alanine, with its three-carbon skeleton, has also been suggested as a possible source. However, fission reactions of longer carbon chains are common and well known, so at present there is no basis to give priority to any specific reaction routes.

\section{Formation of acrylamide through amino acid reactions not involving acrolein}

There are also numerous, plausible reaction routes by which amino acids (or proteins) may form acrylamide without going through acrolein. Within the frame of complex, multistage reaction mechanisms, in volving hydrolyses, rearrangements, decarboxylations, deaminations, etc., many specific mechanistic pathways may be suggested. Decarboxylation and deamination of aspargine, and transformations of dehydroalanine (formed from, e.g. serine or cysteine) are some examples of reaction routes that have been proposed. However, also in this case these can only be seen as possible examples, and similarly to above, there is no basis to give priority to any specific routes.

\section{Conclusion}

Since no systematic studies have been performed or reported, there is at present no evidence to indicate any specific reaction routes for acrylamide formation, or to exclude any possibilities. It is most likely that a multitude of reaction mechanisms is involved, depending on food composition and processing conditions.

\section{Further reactions of formed acrolein and acrylamide}

As mentioned above, acrolein can be converted into acrylamide by a series of fundamental reactions. However, both acrolein and acrylamide are reactive, because of their double bonds and the amino group of acrylamide. They can readily react further with other reactive groups present in the food matrix or formed during the heating process. For example, acrylamide can react with small reactive molecules, such as urea $\left[\mathrm{CO}\left(\mathrm{NH}_{2}\right)_{2}\right]$ and form- 
aldehyde $(\mathrm{HCHO})$, or with glyoxal $\left[(\mathrm{CHO})_{2}\right]$, aldehydes ( $\mathrm{RCHO})$, amines $\left(\mathrm{R}_{2} \mathrm{NH}\right)$, thiols (RSH), etc. Furthermore, the products shown in the following scheme can even react further in the same mode of reaction: reaction system involves many of the basic carbohydrate and amino acid reactions. Another major reaction in foods during processing, which could be of importance, is lipid hydrolysis followed by oxidation of the fatty acids.

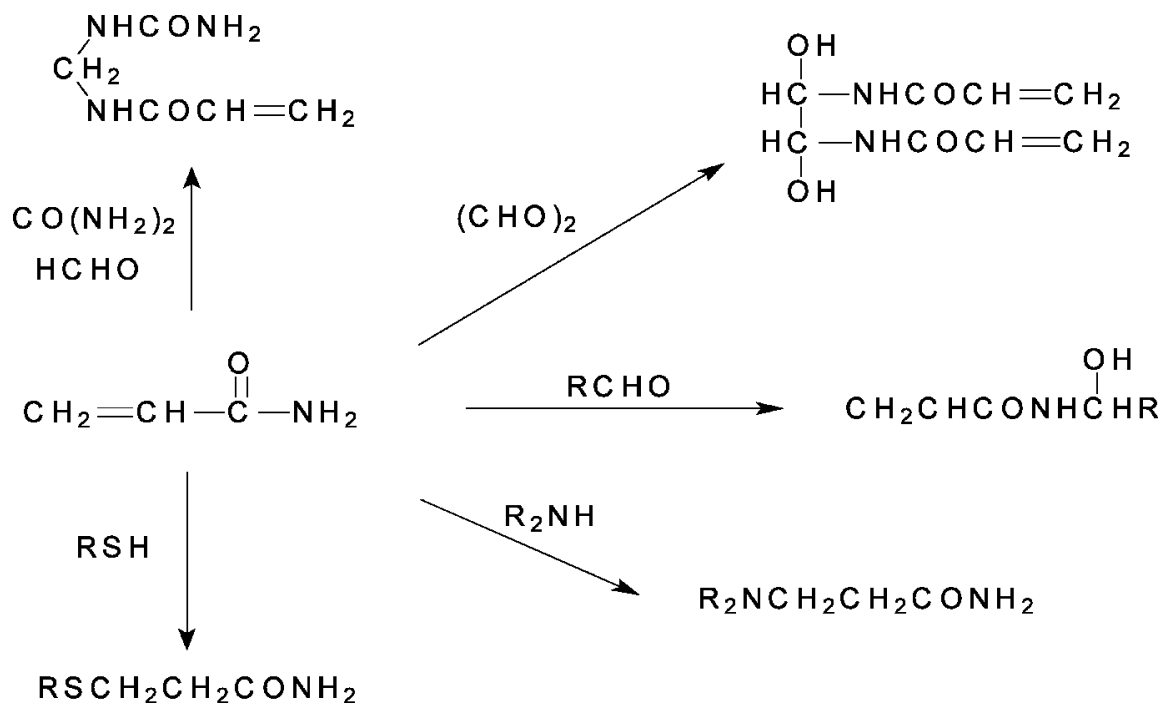

These types of reactive functional group may also be found in macromolecules, such as proteins. (See adduct formation with valine in the globin chain of haemoglobin, described above. In haemoglobin adducts are formed not only with valine, but also with, e.g. cystein.) The presence or absence of reactive groups (or its concentration) in the food matrix may thus be one explanation for differences in final acrylamide content in different food systems. The resulting acrylamide level may be due to a balance between formation and further reactions. The low acrylamide levels in heated meat products could, for instance, depend on adduct formation between acrylamide (or acrolein) and proteins.

\section{Factors with a possible influence on acrylamide formation}

A couple of different chemical mechanisms for the formation of acrylamide has been outlined above. As long as the mechanisms are not confirmed, the influencing factors cannot be established. Thus, what is presented here are attempts to identify what factors would be of importance (regarding processing conditions or product composition) if a specific reaction route were the prevailing one. Specific emphasis is placed on the MR, since this

\section{Acrolein formation from lipids}

Acrolein may be formed from the glycerol part of triglycerides or through oxidation of fatty acids. This means that factors favouring lipid hydrolysis as well as factors favouring lipid oxidation would promote acrolein formation. Temperature is an important factor for both of these reactions. Regarding hydrolysis, $\mathrm{pH}$ may also be of importance and high as well as low $\mathrm{pH}$ may be supposed to favour acrolein formation. Regarding oxidation, lipid composition is of key importance: the higher the degree of unsaturation, the lower the stability. Protection against oxygen and light will limit the oxidation, and pro-oxidants, such as metals, should be avoided. The protective effect of antioxidants should also be taken into account.

\section{The Maillard reaction as the route for acrylamide formation}

The MR has been proposed as a route for acrolein formation. The direct formation of acrylamide through amino acid transformations has also been proposed. These amino acid transformations also involve reactions common in the MR system.

Basics of the Maillard reaction

The MR is one of the most important chemical 


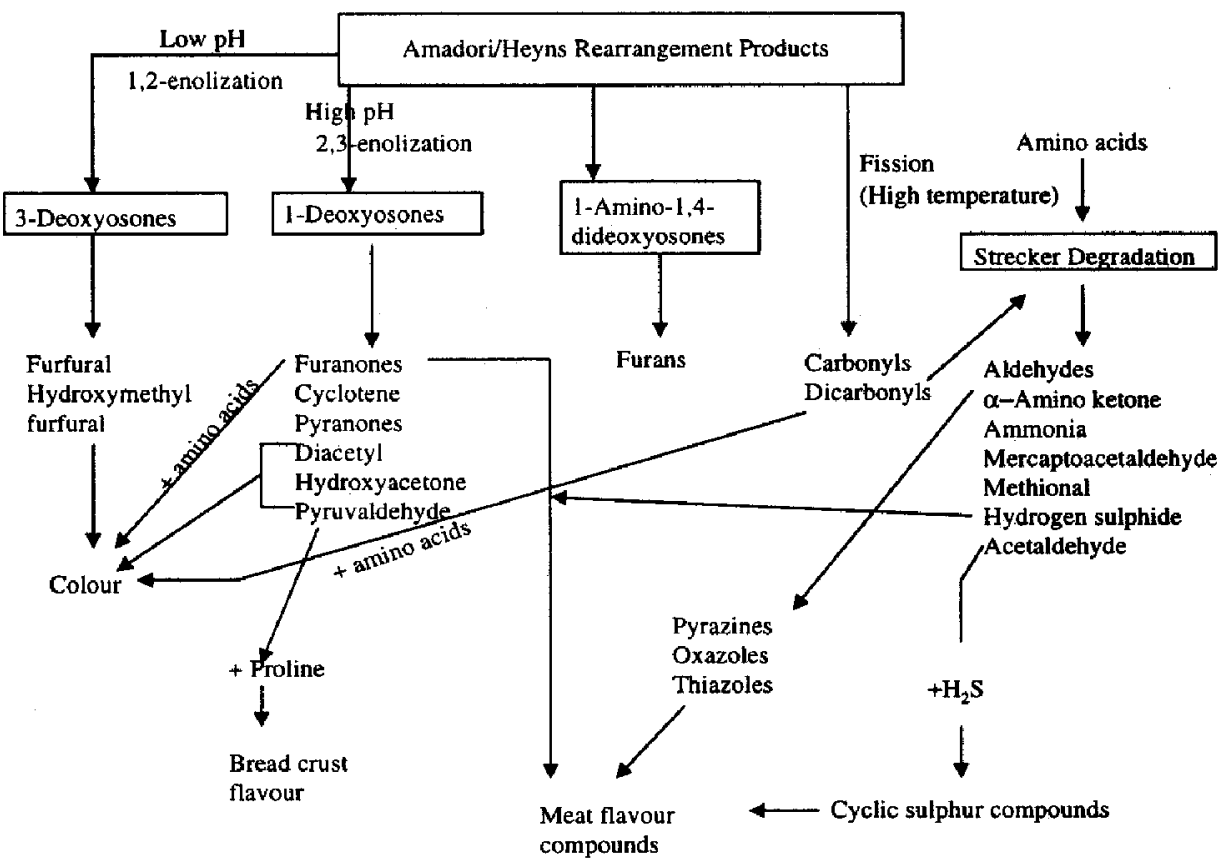

Fig. 1. Pathways of formation of the key flavour intermediates and products in the Maillard reaction. (Published by permission from ref. (43).)

reactions in food processing, with an influence on several aspects of food quality. Flavour, colour and nutritional value may be affected and certain reaction products have been noticed to be antioxidative, antimicrobial, genotoxic, etc. The practical applications of Maillard chemistry in food processing are, therefore, a matter of balance between favourable and unfavourable effects, and the aim of the food manufacturer is to find an optimum in this balance. This may be accomplished by influencing the main variables affecting the MR (42).

The MR takes place in three major stages and is dependent on factors such as concentrations of reactants and reactant type, $\mathrm{pH}$, time, temperature and water activity. Free radicals and antioxidants are also involved (43).

The early stage (step 1) involves the condensation of a free amino group (from free amino acids and/or proteins) with a reducing sugar to form Amadori or Heyns rearrangement products. The advanced stage (step 2) means degradation of the Amadori or Heyns rearrangement products via different alternative routes involving deoxyosones, fission or Strecker degradation. A complex series of reactions including dehydration, elimination, cyclization, fission and fragmentation results in a pool of flavour intermediates and flavour compounds. Following the degradation pathway as illustrated schematically in Fig. 1 , key intermediates and flavour chemicals can be identified.
One of the most important pathways is the Strecker degradation, in which amino acids react with dicarbonyls (formed by the MR) to generate a wealth of reactive intermediates. Typical Strecker degradation products are aldehydes, e.g. formaldehyde, acetaldehyde and possibly propenaldehyde (acrolein). Strecker degradation results in degradation of amino acids to aldehydes, ammonia and carbon dioxide (44) and takes place in foods at higher concentrations of free amino acids and under more drastic reactions, e.g. at higher temperatures or under pressure (45).

The final stage (stage 3 ) of the MR is characterized by the formation of brown nitrogenous polymers and co-polymers. While the development of colour is an important feature of the reaction, relatively little is known about the chemical nature of the compounds responsible. Colour compounds can be grouped into two general classes: low molecular weight colour compounds, which comprise two to four linked rings, and the melanoidins, which have much higher molecular weights.

\section{Review of factors influencing the Maillard reaction}

Factors that are particularly important for the MR are the starting reactants, e.g. type of sugar and amino acid (protein), temperature, time and water activity. The presence of metal salts (pro-oxidants), and inhibitors, such as antioxidants and sulfite, may have an impact. 
Starting reactants: reducing sugar and amino acids / proteins. The MR requires reducing sugars, i.e. sugars containing keto- or aldehydes (free carbonyl groups). The reactivity of different sugars can be summarized in the following way (46):

- The shorter the carbon chain of the sugar, the greater the lysine losses (MR).

- Pentoses are more reactive than hexoses and disaccharides in yielding brown colour.

- Aldoses are more reactive than ketoses both in aqueous solution model systems and at storage (low water content).

- Among isomeric sugars, stereochemistry is important. Thus, ribose is more reactive than xylose monitored as lysine losses.

All monosaccharides are reducing sugars. (Sugar alcohols do not participate in the MR.) Among the disaccharides all sugars except for sucrose are reducing sugars. In oligosaccharides and starch only the end-terminal monosaccharide is a reducing sugar. Starch and sugars, such as sucrose, lactose and maltose, can easily hydrolyse upon heating above $100^{\circ} \mathrm{C}$ at slightly acidic $\mathrm{pH}$, resulting in the formation of monosaccharides (reducing sugars). Thus, thermal processing often results in a continuous supply of reducing sugar formed from complex carbohydrates.

Most studies concerning the reactivity of amino acids have been performed on free amino acids in diluted aqueous solutions. The reactivity among the diamino acids increased with the length of the carbon chain. Among the amino acids studied lysine was most reactive. In proteins and peptides, only free amino groups can react, i.e. $\mathrm{N}$-terminal $\alpha$-amino groups and $\Omega$-amino groups.

Temperature and time. The temperature dependence of chemical reactions is often expressed as the activation energy $\left(E_{\mathrm{a}}\right)$ in the Arrhenius equation. The higher the value of $E_{\mathrm{a}}$, the more temperature dependent the reaction rate. Activation energy data for the MR have been reported within a wide range, 10-160 $\mathrm{kJ} \mathrm{mol}^{-1}$, depending on, among other things, water activity and $\mathrm{pH}$ and what effect of the reaction has been measured. The temperature dependence of the MR is also influenced by the participating reactants. The temperature effect is also affected by the other variables, and different aspects of the MR thus differ in temperature dependence (42).

Water. Water has both an inhibitory and an accelerating impact on the MR. Water acts partly as a reactant and partly as a solvent and transporting medium of reactants (reactant mobility). In the initial steps of the MR, 3 moles of water are formed per mole of carbohydrate. Thus, the reaction occurs less readily in foods with a high water activity $\left(a_{\mathrm{w}}\right)$ value. Water may depress the initial glucosylamine reaction, but enhance the deamination step later in the reaction.

The results from studies in model systems for optimal water concentration or $a_{\mathrm{w}}$ (free water) or relative humidity $(\mathrm{RH})$ vary markedly depending on selected reactants and how the MR is evaluated: as loss in lysine or browning intensity. Several studies have been performed, of which most claim the maximum $a_{\mathrm{w}}$ to be between 0.3 and 0.7 (47). However, most data on the influence of $a_{\mathrm{w}}$ are based on studies at relatively low temperatures $\left(30-60^{\circ} \mathrm{C}\right)$. At higher temperature, more relevant to heat processes, considerably lower $a_{\mathrm{w}}$ has been shown to be favourable to the MR (42).

The main explanation for an optimum reaction rate at an intermediate $a_{\mathrm{w}}$ is that the reactants are diluted at the higher $a_{\mathrm{w}}$, while at a lower $a_{\mathrm{w}}$ the mobility of reactants is limited, despite their presence at increased concentrations.

$p H$. The MR itself has a strong influence on $\mathrm{pH}$. Therefore, aqueous model systems based on reflux boiling of sugars and amino acids need to be buffered since the $\mathrm{pH}$ quickly drops from 7 to 5 . Low $\mathrm{pH}$ values $(<7)$ favour the formation of furfurals (from Amadori rearrangement products), while the routes for reductones and fission products are preferred at a high $\mathrm{pH}$. However, the overall effect of $\mathrm{pH}$ is not clear cut, since the reactions take place by all three pathways. In unbuffered water solutions, $\mathrm{pH}$ decrease during the MR and buffering with alkali have a catalytic effect.

The reactivity of different amino acids at various $\mathrm{pH}$ has been studied. Browning of a glucose solution upon heating was obtained first when $\mathrm{pH}$ exceeded 5 and it increased with increasing $\mathrm{pH}$. The degree of browning varied with the position of the amino group. The function of $\mathrm{pH}$ is linked with specific reaction steps of the MR. Initially, only non-protonized forms of amino acids can form Schiff base. This explains the pronounced change in reactivity (monitored as browning) that happens when $\mathrm{pH}$ passes the isoelectric point of the amino group in the reacting amino acid. Thus, optimal $\mathrm{pH}$ for the MR varies with the system used and how the reaction is monitored (e.g. lysine losses or browning).

Inhibition of the Maillard reaction. Measures to inhibit the MR in cases where it is undesirable 
involve lowering the $\mathrm{pH}$ value, maintenance of the lowest possible temperatures and avoidance of critical water contents (moistures below 30\%, during processing and storage), use of non-reducing sugars and addition of sulfite (45). The use of the inhibitor sulfur dioxide constitutes an important way of controlling the MR. It may combine with early intermediates. However, sulfite only delays colour formation and it is interesting to note that the colour formed in sulfite-treated systems is less red and more yellow than in untreated systems.

\section{Maillard reactions and food processing}

In exploiting the MR, the key target for the food industry is to understand and harness the reaction pathways enabling the improvement of existing products and the development of new products. While it would be easy to assume that this means the generation of flavour and colour, not all Maillard products endow positive characteristics to foods and ingredients. The positive contributions of the MR are flavour generation and colour development. The negative aspects are off-flavour development, flavour loss, discoloration, loss of nutritional value and formation of toxic Maillard reaction products (MRPs). In applying the MR, there are challenges that are common to the food industry, independent of the type of the product. These challenges can be classified: maintenance of raw material quality, maintenance of controlled processes for food production, maintenance of product quality and extension of product shelf-life $(42,43)$.

Flavour/aroma. The most common route for formation of flavours via the MR comprises the interaction of $\alpha$-dicarbonyl compounds (intermediate products in the MR, stage 2) with amino acids through the Strecker degradation reactions. Alkyl pyrazines and Strecker aldehydes belong to commonly found flavour compounds from the MR. For example, low levels of pyrazines are formed during the processing of potato flakes when the temperature is less than $130^{\circ} \mathrm{C}$, but increase 10 -fold when the temperature is increased to $160^{\circ} \mathrm{C}$, and decrease at $190^{\circ} \mathrm{C}$, probably owing to evaporation or binding to macromolecules. The aroma profile varies with the temperature and the time of heating. At any given temperature-time combination, a unique aroma, which is not likely to be produced at any other combination of heating conditions, is produced. Temperature also affects the development of aroma during extrusion cooking.
Colour. The coloured products of the MR are of two types: the high molecular weight macromolecule materials commonly referred to as the melanoidines, and the low molecular weight coloured compounds, containing two or three heterocyclic rings (48). Colour development increases with increasing temperature, time of heating, increasing $\mathrm{pH}$ and intermediate moisture content $\left(a_{\mathrm{w}}=0.3-0.7\right)$. In general, browning occurs slowly in dry systems at low temperatures and is relatively slow in high-moisture foods. Colour generation is enhanced at $\mathrm{pH}>7$. Of the two starting reactants, the concentration of reducing sugar has the greatest impact on colour development. Of all the amino acids, lysine makes the largest contribution to colour formation and cysteine has the least effect on colour formation.

Antioxidative capacity. There are several reports on the formation of antioxidative MRPs in food processing. The addition of amino acids or glucose to cookie dough has been shown to improve oxidative stability during the storage of the cookies. Heat treatment of milk products before spray drying has been reported to improve storage stability, as has heat treatment of cereals (42).

The antioxidant effect of the MRP has been extensively investigated (49). It has been reported that the intermediate reductone compounds of MRP could break the radical chain by donation of a hydrogen atom: MRP was also observed to have metal-chelating properties and retard lipid peroxidation. Melanoidines have also been reported to be powerful scavengers of reactive oxygen species (50). Recently, it was suggested that the antioxidant activity of xylose-lysine MRPs may be attributed to the combined effect of reducing power, hydrogen atom donation and scavenging of reactive oxygen species (51).

Nutritive value. Loss of protein quality is often associated with the MR, especially in cereal products and milk powder produced by heat treatment. Usually the essential amino acid having an extra free amino group, e.g. lysine, is most vulnerable. If the essential amino acid is also the nutritionally limiting amino acid, the influence of the MR on the protein quality is substantial. This is not a problem in cooking meat and fish, since these food items are very rich in protein. Loss of protein quality in terms of nutritional value is a more serious problem for heat treatment and dehydration, especially of cereals, milk and their mixtures (breakfast cereals, gruels, bread, biscuits), since carbohydrates 
dominate over proteins in these food items and the proteins levels are also generally low.

Toxic effects. The possibilities that MRPs could be mutagenic and/or carcinogenic were explored with the Ames test around 20-25 years ago. In general, weak genotoxicity/mutagenic activities were found for known MRPs. Most attention over the past few decades has been paid to the food mutagens found in the crust from cooked meat and fish. Chemically, these compounds belong to a class of heterocyclic amines, currently amounting to around 20 different species. Most of them have been classified as possible food carcinogens (group 2B) by the IARC, based on long-term studies on rodents. The precursors of the heterocyclic amines are free amino acids and, for more than half of the 20 species, also creatine (a natural energy metabolite present in muscle cells only). Reducing sugars up to equimolar amounts compared with amino acids and/or creatine enhance the yields of heterocyclic amines markedly.

Thus, the MR and/or pyrolysis have been claimed to be important mechanisms for the formation of these heterocyclic amines, where Strecker aldehydes, pyrazines or pyridines and creatine have been suggested to play an important role. The yields of these food-borne carcinogens increase with time and temperature, especially from $150^{\circ} \mathrm{C}$ and above. The highest concentrations of heterocyclic amines are found in the crust of panfried, grilled or barbecued meat and fish. In addition, gravies prepared from dried meat juice collected from pan residues or oven roasting could be rich in heterocyclic amines. Pro-oxidants, water activity in the optimal range for the MR and high temperatures $\left(200-400^{\circ} \mathrm{C}\right)$ enhance their yield. The average daily exposure for heterocyclic amines is around $0.5 \mu \mathrm{g}$ per person, with a range between 0 and $20 \mu \mathrm{g}$. Antioxidants, an excess of carbohydrates, cooking temperatures below $200^{\circ} \mathrm{C}$ and moisture contents above $30 \%$ reduce the occurrence of heterocyclic amines. Moreover, heterocyclic amines rarely occur in plant foods, even during well-done cooking (52).

To the authors' knowledge, no reports in the literature so far have studied acrylamide formation linked with the MR.

\section{Conclusions and ideas from data and observations presented so far}

No systematic studies of acrylamide content in food products have yet been published. The
Swedish National Food Administration reported results from their analyses on 23 April 2002, with some new results added on 26 April (http:// www.slv.se/HeadMenu/livsmedelsverket.asp). In most cases the figures reported referred only to one single, randomly selected package of each specific product.

Similar follow-up studies have been reported by the Food Standards Agency in the UK

(17 May; http://www.food.gov.uk/news/

newsarchive/65268),

the Norwegian Food Agency (SNT, 6 June 2002; http://www.snt.no/nytt/tema/Akrylamid/ analyseresultater.htm),

a German laboratory (6 June 2002; http://www. wdr.de/tv/plusminus/aktuell_20020605_2.html),

the Swiss Federal Office of Public Health (13 June 2002; (http://www.bag.admin.ch/verbrau/aktuell/d/ Q\&A_Acrylamide_D.pdf)

and a US organization (25 June 2002, http:// www.cspinet.org).

In all studies single, randomly selected samples were analysed. The main original results reported by the Swedish National Food Administration were confirmed by the later studies, but it must be concluded that substantial variations are found within a given food group and in cases when repeated analyses of the same product have been performed considerable variations have been found between samples. This makes the data premature as a basis for conclusions on the mechanisms for acrylamide formation. An attempt to summarize the results published so far is presented in Table 1.

Table 1, presenting hitherto reported acrylamide data of heat-treated foods, can only give indications as to which factors are important in acrylamide formation. Table 1 indicates that high temperatures are needed for the acrylamide to form. No acrylamide formation has so far been demonstrated at temperatures below $100^{\circ} \mathrm{C}$ and it is probable that the products reported have reached temperatures well above this level. There are several examples of exaggerated acrylamide formation on overheating. Fried products of plant origin seem to give the highest concentrations, but frying fat is not a prerequisite for acrylamide formation.

The data indicate strongly that acrylamide formation is mainly a surface phenomenon. This has also been verified by other data presented to the authors by companies. This implies that water activity may be an important factor, although there are strong links between temperature and water activity in a frying or baking process. 
From the analyses reported it is very difficult to draw conclusions on variations between different plant raw materials. Corn products are possibly lower in acrylamide content than comparable products made from potato or other cereals. However, it is difficult to explain these possible differences or draw conclusions on reaction mechanisms, since detailed data on chemical composition (reducing sugars, specific amino acids, etc.) are lacking. This is a general difficulty. There are insufficient details on chemical composition to be able to suggest which are the important precursors and formation mechanisms.

Some data and observations, however, indicate that acrylamide formation is increased by increased concentration of (reducing) sugar in the raw materials or ingredients. This strongly supports the MR mechanisms. The MR hypothesis is also supported by several other observations, parallel to browning, the influence of temperature and water activity, etc. In fried products the proposed route via acrolein formed from lipids should also be considered. The relatively high temperatures combined with low water activity which favour acrylamide formation,

Table I. Acrylamide data of heat-treated foods

\begin{tabular}{|c|c|c|c|}
\hline \multirow[t]{2}{*}{ Product group } & \multicolumn{3}{|c|}{ Acrylamide concentration $\left(\mu \mathrm{g} \mathrm{kg}{ }^{-1}\right.$ ) } \\
\hline & Typical range & Extreme values & \\
\hline Potato crisps & $600-2000$ & 170 & 2300 \\
\hline French fries ${ }^{\mathrm{a}}$ & $300-700$ & 300 & 3500 \\
\hline Pan-fried potatoes & $250-300$ & & \\
\hline Biscuits and crackers & $100-600$ & $<30$ & 750 \\
\hline Popcorn ${ }^{\mathrm{b}}$ & 400 & & \\
\hline Crispbreads & $50-400$ & $<30$ & 4000 \\
\hline Coffee (powder) & 200 & 170 & 230 \\
\hline Breakfast cereals & $50-250$ & $<30$ & 1350 \\
\hline Corn crisps & $100-200$ & 30 & 420 \\
\hline Soft breads & $<30-50$ & $<30$ & 160 \\
\hline Meat and fish products & $<30-50$ & $<30$ & 60 \\
\hline $\begin{array}{l}\text { Pizza, pancakes, waffles, } \\
\text { scrambled egg }\end{array}$ & $<30$ & $<30$ & 40 \\
\hline $\begin{array}{l}\text { Raw, boiled or mashed } \\
\text { potatoes }\end{array}$ & $<30$ & & \\
\hline Pasta & $<30$ & & \\
\hline $\begin{array}{l}\text { Wheat and rye flour, } \\
\text { rice, oat flakes }\end{array}$ & $<30$ & & \\
\hline $\begin{array}{l}\text { Vegetarian schnitzel, } \\
\text { cauliflower gratin }\end{array}$ & $<30$ & & \\
\hline Dried fruit ${ }^{\mathrm{b}}$ & $<30$ & & \\
\hline Beer (alcohol free) ${ }^{b}$ & $<30$ & & \\
\hline
\end{tabular}

${ }^{\text {a }}$ For deliberately overcooked samples, values as high as $12,800 \mu \mathrm{g} \mathrm{kg}^{-1}$ have been reported.

${ }^{\mathrm{b}}$ One single value. also favour free radical reactions. Thus, antioxidants and other free radical scavengers or quenchers could act as inhibitors.

The MR occurs wherever non-enzymic browning is induced by heat treatment, e.g. extrusion cooking, roasting, popping, baking, pan-frying, deep-fat frying, barbecuing and autoclavation. Most unprocessed foods contain the necessary starter reactants, i.e. amino acids/proteins and reducing sugar. Conventionally cooked foods are subjected to a relatively high temperature for a relatively long time, and the surface of the food dries out to give a crust with a low $a_{\mathrm{w}}$, favouring the MR.

It is also clear from the composition of cereals and potato (see below), and most other raw food material, that they contain all necessary precursors, e.g. protein/free amino acids, carbohydrates/sugars and lipids, to initiate both MRs and lipid oxidation or other degradation routes during processing and storage. The extent to which these foods contain the optimal proportion of precursors and modifying components in terms of enhancers or inhibitors for acrylamide formation remains to be established.

In this context one must also bear in mind the high potential for acrylamides to be consumed through further reactions with other components in the food product. Similarly, acrolein or other precursors could react with other food components and take reaction routes not leading to acrylamide. Consequently, the final acrylamide level in a food product may be due to the balance between formation and further reactions, controlled by the chemical composition of that specific food. Low acrylamide levels may thus be a result of further reactions (or altered reaction routes) in that specific food matrix. As already speculated, the low acrylamide levels demonstrated in meat products could be a result of adduct formation of acrylamide with proteins or other components. All of the reaction mechanisms mentioned so far (MR, lipid hydrolysis and oxidation, etc.) are also known to proceed in meat systems.

\section{Raw material composition}

The raw material studied so far has been mainly cereals and potato, and as shown in Table 1, heattreated products from these materials contain the highest concentrations of acrylamides, in several samples exceeding $500 \mu \mathrm{g} \mathrm{kg}^{-1}$. These plant materials are storage organs containing large quantities of starch, protein and cell-wall materials as well as lipids, ash, polyphenols and a large number of low molecular weight compounds such as sugars and 
free amino acids. It is well known that there exists a large variation in chemical composition in most plant materials. This variation is dependent on both genetic and environmental factors. The main mechanisms for acrylamide formation discussed so far are related to fat degradation and reactions involving sugars, amino acids and proteins, not the least the MR. Other components such as starch and dietary fibre may be involved by modulating the processing conditions, such as the water activity.

On a dry matter basis, wheat contains $60-73 \%$ starch, 9-16\% crude protein, 9-18\% dietary fibre, $2-3 \%$ fat, 2-5\% sugars (glucose, fructose and fructo-oligosaccharides as well as maltose in germinated products) and $1-2 \%$ ash. The crude protein contains all the common amino acids and also significant amounts of free amino acids. Rye and dehulled oats contain less starch but more dietary fibre, especially water-soluble and viscous dietary fibre. Oats also have a higher content of fat, which in this cereal is also present in the starchy endosperm. Rye has a higher content of sugars, especially fructo-oligosaccharides. Corn has higher starch and fat contents, but a lower content of dietary fibre than wheat.

On a dry matter basis, potato contains $60-80 \%$ starch, 3-13\% crude protein, 3-8\% dietary fibre, $0.1-1 \%$ fat, $0.5-4.5 \%$ (mainly glucose, fructose and sucrose) and 4-6\% ash. In immature or stored potato the content of sugars may be much higher.

\section{Analytical methods: can we trust the data?}

The methods used to analyse acrylamide in foods were described briefly in the background section. GC-MS methods and LC-MS/MS methods have been used. Analyses have now been performed by a number of laboratories (using somewhat different methods). When the same type of product has been analysed in several countries, generally good agreement has been obtained between the results. Good correlation has also been demonstrated when identical samples have been analysed by different methods at different laboratories (13). This strongly supports that the analytical methods are reliable, that it really is acrylamide that is measured, and that the reported data can be trusted. Further support comes from the finding that $\mathrm{Hb}$ adduct levels in animals tallied with aclylamide intake as analysed in the feed (11). Similar conclusions can be drawn from adduct levels in humans and human consumption of heated foods (12).

The same conclusion was reached by the Food and Agriculture Organization/World Health Orga- nization (FAO/WHO) Consultation in Geneva, on 25-27 June 2002. Their summary report states: "Sensitive and reliable methods are available to identify and measure acrylamide in foodstuffs. The measurement uncertainty is small in relation to the between-sample and within-lot variability expected for acrylamide levels " (http://who.int/fsf).

\section{Conclusions}

The exact chemical mechanisms of acrylamide formation in heated foods are not known. Several plausible mechanistic routes may be suggested, involving reactions of carbohydrates, proteins/amino acids, lipids and probably also other food components as precursors. With the data and knowledge available today it is not possible to point out any specific routes, or to exclude any possibilities. A multitude of reaction mechanisms is probably involved, depending on food composition and processing conditions. Acrolein is one strong precursor candidate. Current data indicate that the MR may be an important reaction route for acrylamide formation, but lipid degradation pathways to the formation of acrolein should also be considered.

Acrylamide is a reactive molecule and it can readily react with various other components in the food. The actual acrylamide level in a specific food product therefore probably reflects the balance between ease of formation and the potential for further reactions in that food matrix.

More research is needed before any firm conclusions can be drawn concerning precursors, reaction route(s) and conditions for acrylamide formation in terms of reactants, time, temperature, $\mathrm{pH}$, water activity, etc. More data regarding acrylamide levels in a broader range of food products are also needed. Reliable analytical methods to measure acrylamide in foods are available.

\section{Research needs: suggestions for further studies}

Model studies, based on current hypotheses, to identify chemical mechanisms for acrylamide formation (precursors, reaction conditions, possible inhibitors, etc.);

- model studies to elucidate possible further reactions between acrylamide and other food components;

- kinetic studies of acrylamide formation in model systems;

- studies in foods/food models: influence of processing parameters; influence of ingredients/possible precursors; 
- optimization of formulation and processing conditions to minimize acrylamide levels, taking into consideration other product quality properties;

- continued mapping of acrylamide and acrolein in different foods;

- development of simple methods to measure acrylamide in foods.

\section{Could anything be done while awaiting the final answers?}

The knowledge is still too limited to draw conclusions regarding cooking practices during industrial processing or food preparation at home. More answers from further research are needed. In the meantime the only obvious practical advice would be to avoid overheating. As long as the chemical mechanisms remain unknown, further practical recommendations are difficult to make. However, there are some indications that the MR could be involved, suggesting that factors such as levels of free (reducing) sugars and amino compounds in raw materials and ingredients should be taken into consideration. Although there is little available information on the possible influence of lipids, an interim piece of advice would be to be aware of this possibility and to control lipid degradation and oxidation in frying oils as far as possible, until more knowledge is obtained about this.

\section{Postscript}

During the publishing of this article the first reports on the chemical mechanisms of acrylamide formation were presented. They all showed that acrylamide can be formed by a reaction between amino acid and sugar, and identified asparagine as a main amino acid.

- Becalski A, Lau BP-Y, Lewis D, Seaman S. Acrylamide in foods; occurrence and sources. Poster at the AOAC Annual Meeting, Los Angeles, CA, 22-26 September 2002.

- Mottram DS, Wedzicha BI, Dodson AT. Acrylamide is formed in the Maillard reaction. $\mathrm{Na}$ ture 2002; 419: 448.

- Sanders RA, Zyzak DV, Stojanovic M, et al. An LC/MS acrylamide method and its use in investigating the role of asparagines. Presentation at the AOAC Annual Meeting, Los Angeles, CA, 22-26 September 2002.

- Stadler RH, Blank I, Varga N, et al. Acrylamide from Maillard reaction products. Nature 2002; 419: 449.

\section{References}

1. IARC. Monographs on the evaluation of carcinogen risk to humans: some industrial chemicals. No. 60. Lyon: International Agency for Research on Cancer; 1994.

2. European Union. European Union Risk Assessment Report. Acrylamide. Draft Report (forthcoming).

3. Törnqvist M. Epoxide adducts to $\mathrm{N}$-terminal valine of hemoglobin. In: Everse J, Vandegriff KD, Winslow RW, eds. Meth Enzymol 1994;650-7.

4. Törnqvist M, Fred C, Haglund J, et al. Protein adducts: quantitative and qualitative aspects of their formation, analysis and applications. J Chromat B 2002;778;279308.

5. Bergmark E, Calleman CJ, Costa LG. Hemoglobin adducts in humans occupationally exposed to acrylamide. Toxicol Appl Pharmacol 1993;120:45-54.

6. Bergmark E. Hemoglobin adducts of acrylamide and acrylonitrile in laboratory personnel, smokers and nonsmokers. Chem Res Toxicol 1997;10:78-84.

7. Licea Pérez H, Cheong HK, Yang JS, OstermanGolkar S. Simultaneous analysis of hemoglobin adducts of acrylamide and glycidamide by gas chromatography-mass spectrometry. Anal Biochem 1999;274:5968.

8. Hagmar L, Törnqvist M, Nordander C et al. Health effects of occupational exposure to acrylamide using hemoglobin adducts as biomarkers of internal dose. Scand J Work Environ Health 2001;27:219-26.

9. Paulsson B, Grawé J, Törnqvist M. Hemoglobin adducts and micronucleus frequencies in mouse and rat after acrylamide or $\mathrm{N}$-methylolacrylamide treatment. Mutat Res 2002;516:101-11.

10. Törnqvist M, Bergmark E, Ehrenberg L, Granath F. [Risk assessment of acrylamide]. Sweden: National Chemicals Inspectorate; 1998. PM 7-98. (In Swedish.)

11. Tareke E, Rydberg P, Karlsson P et al: Acrylamide: a cooking carcinogen? Chem Res Toxicol 2000;13:51722.

12. Tareke E, Rydberg P, Karlsson P, et al. Analysis of acrylamide; a carcinogen formed in heated foodstuffs. $J$ Agric Food Chem 2002;50;17:4998-5006.

13. Rosén J, Hellenäs KE. Analysis of acrylamide in cooked foods by liquid chromatography tandem mass spectrometry. Analyst 2002;127;7:880-882.

14. Schmiedel P, Jekel M, Gassenmeier T, et al. Particle compositions containing active substance and substance with lower critical solution temperature for controlled release. German patent; Chem Abstr 2001;135:21255.

15. Takeshita R, Sakagami Y, Kuzuhara, Y, et al. Food additives (food preservatives, artificial sweeteners). VIII. Detection of 2-(2-furyl)-3-(5-nitro-2-furyl)acrylamide in foods by thin-layer chromatography. Shokuhin Eiseigaku Zasshi 1967; 8: 124-6; Chem Abstr 1967; 68: 86162.

16. Ohara S. Manufacture of modified novolak epoxy coating compositions for food cans. Japanese patent. Chem Abstr 2002; 136: 280874. 
16. Ohara S. Manufacture of modified novolak epoxy coating compositions for food cans. Japanese patent. Chem Abstr 2002; 136: 280874.

17. Shibasaki I. Comparison of tylosin and 2-furyl-3-(5-nitro-2-furyl)acrylamide as food preservatives. Nippon Shokuhin Kogyo Gakkaishi 1964; 11: 415-9; Chem Abstr 1964; 64: 87647.

18. Kawana K, Nakaoka T, Wada Y. Behavior of 2-(2furyl)-3-(5-nitro-2-furyl)acrylamide in foods. I. Decomposition of 2-(2-furyl)-3-(5-nitro-2-furyl)acrylamide to acrylamide. Kanagawa-ken Eisei Kenkyusho Kenkyu Hokoku 1974; 4: 35-40; Chem Abstr 1974; 85: 3958.

19. Barvenik F, et al. Polymer use in food processing wastes for recycle into animal feed, Conference: Utilizacion de Aguas Regeneradas y Biosolidos, Malaga, Spain, 6-9 April 1997; Chem Abstr 1997; 130: 13399.

20. Arikawa A, Shiga M. Determination of trace acrylamide in the crops by gas chromatography. Bunseki Kagaku 1980; 29: 33-9; Chem Abstr 1980; 93: 202742.

21. Schultzova J, Tekel J. Acrylamide monomer occurrence in sugar. Dtsch Lebensm-Rundsch 1996; 92: 281-2; Chem Abstr 1996; 125: 326762.

22. Tezer N, Ozkan R. Mechanisms and transition structures for conjugate and carbonyl addition of ammonia to three small alpha, beta-unsaturated carbonyl compounds: an ab initio molecular orbital study. J Mol Struct Theochem 2001;546:79-88.

23. Rossner J, et al. Strecker degradation products of aspartic and glutamic acids and their amides. Czech $\mathbf{J}$ Food Sci 2001; 19: 41-5; Chem Abstr 2001; 135: 272077.

24. Adamiec J, et al. Novel Strecker degradation products of tyrosine and dihydroxyphenylalanine. Czech J Food Sci 2001; 19: 13-8; Chem Abstr 2001; 135: 61521.

25 . Ishizuka $S$, et al. Reaction products produced from the reaction of dehydroascorbic acid with methionine. $\mathrm{Ni}$ hon Daigaku Nojuigakubu Gakujutsu Kenkyu Hokoku 1979; 36: 111-20; Chem Abstr 1979; 90: 202457.

26. Bucko A, Ondreicka R, Simko V, Babala J. [Physical and chemical changes and biological effects of heat treated edible oils]. Cesk Gastroenterol Vyziva 1971; 25: $109-15$.

27. Arnaiz-Lopez AM, Permanyer-Fabregas JJ. [Application of HPLC to the determination of acrolein in heated oils]. Rivista Italiana delle Sostanze Grasse 1986; 63: $605-8$.

28. Umano K, Shibamoto T. Analysis of acrolein from heated cooking oils and beef fat. J Agric Food Chem 1987;35:909-12.

29. Walradt JP, Pittet AO, Kinlin TE, Sanderson A. Volatile components of roasted peanuts. Abstracts of Papers: American Chemical Society 1970; 160: AGFD70 (FSTA; AN: 71-03-J0294).

30. Antal Jr MJ, Mok WSL, Roy JC, Raissi AT. Pyrolytic sources of hydrocarbons from biomass. J Anal Appl Pyrolysis 1985;8:291-303.

31. Shibasaki K, Motoki M, Kimura S. [Food chemical studies of soybean phospholipids. VII. On the compounds from autoxidized 3-sn-phosphatidylcholine].
Nihon Shokuhin Kogyo Gakkai shi [J Food Sci Technol] 1969; 16: 564-8.

32. Selke E, Rohwedder WK, Dutton HJ. Volatile components from trilinolein heated in air. J Am Oil Chem Soc 1980;57:25 -30.

33. Selke E, Frankel EN. Dynamic headspace capillary gas chromatographic analysis of soybean oil volatiles. J Am Oil Chem Soc 1987;64:749-53.

34. Matthews RF, Scanlan RA, Libbey LM. Autoxidation products of 2,4-decadienal. J Am Oil Chem Soc 1971;48:745-7.

35. Esterbauer H, Schaur RJ, Zollner H. Chemistry and biochemistry of 4-hydroxynonenal, malonaldehyde and related aldehydes. Free Rad Biol Med 1991;11:81128.

36. Uchida K, Kanematsu M, Morimitsu Y et al. Acrolein is a product of lipid peroxidation reaction: formation of free acrolein and its conjugate with lysine residues in oxidized low density lipoproteins. J Biol Chem 1998;273:16058-66.

37. Manley $\mathrm{CH}$, Fagerson IS. Aroma and taste characteristics of hydrolyzed vegetable protein. Flavour Ind 1971; 2: 686-90; Chem Abstr 1971; 76: 98178.

38. Jo C, Ahn DU. Production of volatile compounds from irradiated oil emulsion containing amino acids or proteins. J Food Sci 2000; 65: 612-6; Chem Abstr 2000; 135: 151849.

39. Coultate TP, ed. Food. The chemistry of its components. 2nd edn. London: Royal Society of Chemistry; 1988. p. 20-2.

40. Alarcon RA. Formation of acrolein from various amino acids and polyamines under degradation at $100^{\circ} \mathrm{C}$. Environ Res 1976; 12: 317-26; Chem Abstr 1976;87:10800.

41. Ferretti A, Flanagan V. Lactose casein (Maillard) browning system: volatile components. J Agric Food Chem 1971; 19: 245-9; Chem Abstr 1971; 75: 87231.

42. Lingnert H. Development of the Maillard reaction during food processing. In: Finot PA, Aeschbacher HU, Hurrell RF, Liardon R, eds. The Maillard reaction in food processing, human nutrition and physiology. Advances in Life Sciences. Basel: Birkhauser; 1990. p. $171-84$.

43. Mlotkiewicz J. The role of the Maillard reaction in the food industry. In: O'Brien J, Nursten HE, James M, Crabbe C, Ames J, eds. The Maillard reaction in foods and medicine. London: Royal Society of Chemistry; 1998. p. 19-28.

44. Fennema O. Food chemistry. 3rd edn. New York: Marcel Dekker, 1996. p. 171-4; 412-4.

45. Belitz H-D, Grosch W. Food chemistry, 2nd edn. Springer 1999:257-67.

46. Adrian J. Nutritional and physiological consequences of the Maillard reaction. World Rev Nutr Diet 1974;19:71.

47. Eichner K, Karel M. The influence of water content and water activity on the sugar-amino browning reaction in model systems under various conditions. J Agric Food Chem 1972;20:218. 
48. Ames J, Bailey RJ, Mann J. Recent advances in the analysis of coloured Maillard reaction products. In: O'Brien J, Nursten HE, James M, Crabbe C, Ames J, eds. The Maillard reaction in foods and medicine. London: Royal Society of Chemistry; 1998. p. 76-82.

49. Yen G-C, Liu M-L. Antioxidant and prooxidant activity of xylose-lysine Maillard reaction products. In: O'Brien J, Nursten HE, James M, Crabbe C, Ames J, eds. The Maillard reaction in foods and medicine. London: Royal Society of Chemistry; 1998. p. 231.

50. Hayase F, Hirashima S, Okamoto G, Kato H. Scavenging of active oxygens by melanoidines. Agric. Biol. Chem 1989; 53: 3383-5.
51. Yen GC, Hsieh PP. Antioxidative activity and scavenging effects on active oxygen-lysine Maillard reaction products. J Sci Food Agric 1995;67:415-20.

52. Skog KI, Johansson M, Jägerstad M. Carcinogenic heterocyclic amines in model systems and cooked foods: a review on formation, occurrence and intake. Food Chem Toxicol 1998;36:879-96.

Hans Lingnert

SIK, The Swedish Institute for Food and Biotechnology

Box 540I

SE-402 29 Göteborg

Sweden

E-mail: hl@sik.se 